\title{
A CRÍTICA DE SCHMITT E DE HEGEL AO LIBERALISMO
}

Cesar Augusto RAMOS ${ }^{1}$

- RESUMO: O artigo pretende apresentar a filosofia política do liberalismo a partir das análises críticas de Schmitt e de Hegel. O primeiro fundamenta sua crítica de um ponto de vista do "existencialismo político"; o segundo, com base na racionalidade do Estado moderno. Ambos ressaltam o valor positivo do Estado e criticam a negação do político operada pelo liberalismo.

- PALAVRAS-CHAVE: Liberalismo; Estado; política.

Após a morte de Hegel, em 1831, a idéia hegeliana da especificidade do político e sua irredutibilidade a outras esferas da vida humana encontra, na corrente marxista, crítica feroz. Também o liberalismo se opõe à pretensão hegeliana de pensar o Estado e a política como fundamento de sociabilidade.

Em campos diferentes, tanto a teoria marxiana como a liberal - ambas inimigas figadais entre si, mas aliadas no combate à idéia de autonomia da política e à primazia do Estado - acabaram determinando, no século XX, o campo da análise na Filosofia política, colocando em dúvida a pretensão hegeliana de ver no político o fator dominante, e no Estado o caráter totalizante da sociabilidade.

No contexto da crítica marxista da economia burguesa e na ênfase à subordinação do político ao econômico operada pela ideologia burguesa, Marx pretende justamente denunciar nas sociedades capitalistas modernas as contradições da autonomia do político.

Se Marx percebeu o processo de ideologização da política na sociedade burguesa, faltou-lhe o aprofundamento da especificidade do político como objeto autônomo da análise filosófica. Marx insiste sobre a impossibilidade desta pretensão, pois na

1 Professor de Filosofia Política do Departamento de Filosofia - Universidade Federal do Paraná - 80060-150 Curitiba - PR - Brasil. 
sociedade burguesa a determinação do político pelo econômico impede a autonomização đeste último.

O ocultamento do político por parte da sociedade burguesa determinou, do lado da teoria marxiana, o "esquecimento" do político. O próprio Schmitt percebe esta contradição ao afirmar que o marxismo permanece no século XIX essencialmente marcado por categorias teóricas econômicas.

Na segunda década do século XX, Schmitt, de forma anacrônica e na perspectiva conservadora, se opõe ao liberalismo. Defende o conceito de político como pressuposto para o Estado, e a sua especificidade o elemento que o distingue como fenômeno exclusivamente político. O objeto da análise schmittiana não é a política (die Politik), mas o político (das politische), um adjetivo substantivado.

Assegurar a instância do político como esfera existencial para Schmitt, ou racional para Hegel, constitui recurso teórico necessário à compreensão dos Estados modernos. Ambos acabam por constituir uma linha filosófica crítica da tendência liberal - já presente na época de Hegel, e bastante forte e envolvente no século XX de negação do político e a sua conseqüente instrumentalização social e econômica. É essa "despolitização" do político, levada a cabo pelo projeto liberal, que Hegel e Schmitt criticam com referenciais teóricos distintos.

Hoje, na assim chamada crise da esquerda - num momento em que a direita se apropriou de tradicionais termos da esquerda como autonomia, liberdade, dignidade humana etc. -, a obra de Schmitt e a de Hegel podem lançar alguma luz sobre o pensamento político atual, particularmente quanto ao avanço do neoliberalismo e à negação do político. Ambos compartilham da concepção política da necessidade da esfera pública do Estado e da sua especificidade em relação à lógica constituidora da sociabilidade privada.

A crítica ao liberalismo tem se apresentado, tradicionalmente, como "crítica de direita" e "crítica de esquerda". Rousseau e, principalmente, Marx compartilham desta última, denunciando no liberalismo uma nova forma de alienação do homem. Marx acusa o caráter ideológico de que se reveste o liberalismo quando mistifica a liberdade individual do homem e o seu caráter burguês de apresentação de ser universal e intemporal. A "crítica de esquerda" deriva, no limite, para a negação do Estado como meio político de instrumentalização da ideologia burguesa (liberal). Paradoxalmente, a desconfiança marxiana em relação ao Estado vai ao encontro da máxima liberal de ver o Estado como um "mal necessário". Liberalismo e marxismo demonstram afinidades, pelo menos quanto ao ideal utópico de uma sociabilidade transparente, pacificada e autárquica que realiza para além da esfera "opressora" do Estado. Em última instância, tanto o marxismo como o liberalismo comungam do mesmo desiderato: a concepção que vê o Estado como algo negativo, em que a categoria do político não pode se afirmar como instância autônoma, pois ela é mero instrumento para realização dos interesses privados. 
A "crítica de direita" 2 de Schmitt pode ser resumida na afirmação da autonomia do político e no valor positivo que este mantém no seu necessário vínculo com o Estado. A posição de Schmitt é mais ampla, menos utópica. Ela aponta para a relação entre a neutralização da vida política no século XX e o ideário liberal de negação do político.

A crítica de Schmitt visa restaurar o político em relação ao abandono produzido pela lógica da racionalidade liberal-burguesa. Procura mostrar que a determinação do político pelo econômico é uma forma de neutralização do primeiro, ocultando, assim, a sua natureza: a de possuir dinâmica própria, cujo elemento essencial exprime-se na potência do mando do poder de decisão da autoridade política.

O objetivo de Schmitt é capturar o político como ponto de partida, como uma realidade impossível de negar, tirando-o do desprezo conceitual lançado pelo liberalismo. No comentário de Strauss, "a tarefa de Schmitt é determinada pelo fato do fracasso do liberalismo... o liberalismo negou a política, mas, no entanto, ele não a eliminou do universo: ele simplesmente ocultou a política" ${ }^{3}$ O propósito de Schmitt, continua Strauss, consiste em reafirmar o político, colocá-lo em "plena luz", mais que isso: legitimar um sistema que "reconheça o político".

A análise de Schmitt do esquecimento do político, operada pelo liberalismo, tem um significado mais amplo e alcança a própria concepção de mundo de inspiração liberal. Essa concepção, baseada na crença da ação neutra (não política) da racionalidade da eficácia administrativa-burocrática, resulta contraditória em virtude do descompasso entre as estruturas da racionalidade econômica-produtiva e os mecanismos decisórios do ordenamento político-institucional. Contradição entre aquilo que é especificamente político e a pretensão do ideário liberal de impor um modelo racional não político (ético e econômico) para análise da realidade social. Com base nessa visão de mundo, o liberalismo "não encontrou nenhuma teoria positiva do Estado e nenhuma reforma própria ao Estado, mas procurou, isto sim, prender o político ao ético e subordiná-lo ao econômico" (Schmitt, 1992, p.88).

Aos olhos de Schmitt, o liberalismo surge, modernamente, como uma "nova fé", uma crença que pretende instaurar de forma definitiva, e graças à racionalização da vida, a paz universal e segurança entre os homens, deslocando assim o político para a ordem da racionalidade ética e econômica. Com base nessa apresentação crítica do liberalismo, a análise schmittiana avança com o objetivo de destacar as seguintes características do pensamento liberal como conseqüências do deslocamento do polí-

2 Essa "crítica de direita" tem a ver com a formação antiliberal de Schmitt e com o seu catolicismo conservador que remonta aos anti-revolucionários Joseph de Maistre, de Bonald e, principalmente, Donoso Cortés (1809-1853), autor do ensaio sobre Catolicismo, Liberalismo e Socialismo. Esse sentimento contra-revolucionário induz Schmitt a uma forte rejeição da politica moderna, representada pelo liberalismo. Schmitt, crítico de "direita" da sociedade e pensador católico conservador, adota posição antiiluminista e denuncia o caráter racionalista da política presente no normativo liberal como fator decisivo para a negação do político.

3 Strauss, L. Observação sobre o Conceito do Político, in: Schmitt, 1988a, p.190. 
tico: o individualismo, a despolitização-neutralização do político e a metafísica da discussão.

O antiliberalismo de Schmitt deriva, em parte, da concepção que ele tem do homem, a qual remonta à visão "pessimista" da tradição hobbesiana: uma antropologia negativa, em que o conflito participa de forma imanente das ações humanas, particularmente aquelas que configuram relações políticas. Já a tradição liberal adota um ponto de vista otimista em relação à natureza humana: o indivíduo é detentor, por direito natural, de certos direitos fundamentais a ele atribuídos. Dentre esses direitos, singularmente considerados, sobressai a liberdade (individual). A inexistência de tensão conflitual, quer na investidura originária desses direitos, quer na atuação dos indivíduos nas relações intersubjetivas, induz a uma concepção otimista da natureza humana no horizonte antropológico da concepção liberal.

O individualismo desta concepção, criticado por Schmitt, já aparece na sua origem com os filósofos do direito natural, na formulação de uma hipótese sobre a natureza humana que fornece uma base filosófica de fundo individualista para a vida ética, social e política dos homens. Baseando-se nessa abstração, Locke, por exemplo, afirma com a autoridade de um dos pais do liberalismo moderno, que o estado de natureza originário é um estado de perfeita liberdade e igualdade, no qual governa a lei da natureza que "ensina a todos os homens que tão-só a consultem, sendo todos iguais e independentes, ninguém deve prejudicar a outrem na vida, na saúde, na liberdade ou nas posses" (Locke, s.d., p.6). Com base na primazia do indivíduo e dos seus direitos subjetivos, a política e o Estado são derivações da questão básica dos direitos individuais. $O$ poder político não possui autonomia, ele participa da própria lógica dos interesses individuais. O decisivo não é a discussão sobre a natureza do Estado e da política, mas a forma e os mecanismos de limitação do poder estatal, o qual é visto de forma negativa em contraposição à positividade da natureza humana.

Para Schmitt (1992, p.67), todo e qualquer individualismo não pode conduzir a uma "própria e positiva teoria do Estado e da política". O liberalismo, baseado nas liberdades individuais e na propriedade privada, é antes uma denúncia às restrições a estes princípios e direitos individuais do que propriamente a construção de uma teoria política. "A desconfiança crítica frente ao Estado e à política se esclarece facilmente a partir dos princípios de um sistema para o qual o indivíduo (der Einzelne) tem de permanecer terminus a quo e terminus ad quem" (Idem, p.98). O indivíduo, constituído de forma absoluta como o pressuposto, subordina o direito público ao direito privado independentemente da ordem política. "Todo estorvo, toda ameaça à liberdade individual, em princípio ilimitada, à propriedade privada e à livre concorrência é chamada de 'violência' e é, eo ipso, algo de ruim" (Idem, ibid.). A constituição de um Estado passa a ser um sistema de garantias das liberdades, e tem por objetivo a proteção do cidadão contra o abuso do poder do Estado. "Para a linguagem do liberalismo burguês, só há uma Constituição quando estão garantidas a propriedade privada e a liberdade pessoal; qualquer outra coisa não é Constituição, mas despotis- 
mo, ditadura, escravidão ou como se queira chamar" (Idem, p.59). Por isso, o Estadó para o liberalismo dever ser limitado, controlado pela associação dos indivíduos, precisamente porque o ponto de partida é o sujeito e a liberdade individual. São esses direitos e garantias individuais que impregnam de forma ideal a Constituição de um Estado de Direito. Obviamente, Schmitt não afasta como finalidade do Estado as garantias e os direitos individuais; ressalta apenas que o componente político do Estado não pode ser reduzido e nem ser uma realidade subordinada a um mero instrumento ou ser reduzida a uma "idealidade normativa".

A crítica schmittiana ao liberalismo vincula-se, portanto, à relação que o autor vê entre a ideologia liberal da ênfase ao indivíduo e a conviç̧ão da burguesia num otimismo social da bondade e perfectibilidade do homem. Enfim, a crença numa harmonia natural da sociedade com base no livre jogo dos interesses individuais que leva os indivíduos a uma adequação não conflituosa no conjunto da sociedade. A conseqüência desse modo de pensar é a despolitização do homem, a dissolução da existência humana no nilismo, a dependência da política à técnica e a um moralismo humanitário.

Uma segunda característica importante do liberalismo, objeto da crítica de Schmitt, é a despolitização-neutralização do político. Na concepção da filosofia da história schmittiana, a história européia passou nos 400 últimos anos pelas seguintes etapas: a etapa teológica, a metafísica, a moral e a econômica. A racionalidade científica da técnica da etapa econômica atual substitui a controvérsia de fundo teológico e metafísico pelo domínio neutro da técnica que anula o conflito, produzindo uma neutralização do espírito. A força da técnica, comumente disseminada nos nossos dias, decorre do fato de se acreditar ter encontrado nela uma esfera absoluta e definitivamente neutra de conhecimento. Como afirma Schmitt, em relação às questões morais, econômicas e políticas, as quais propiciam espaço para disputas, os problemas puramente técnicos têm uma objetividade que é reconfortante: "eles conhecem soluções evidentes".

Se Schmitt caracteriza a modernidade como a era da despolitização, é porque nela os valores que orientam a vida política são constituídos no terreno da neutralização dos conflitos, cujo paradigma é dado pela racionalidade técnica. Com base na cultura da neutralidade, o ideal da ação política deve pairar acima dos conflitos, buscando o consenso (pelo menos na maioria) e estabelecendo a paz.

Toda briga e confusão da contenda confessional, nacional e social vem a ser nivelada em um terreno completamente neutro. A esfera da técnica pareceu ser uma esfera da paz, do entendimento e da reconciliação. A conexão da fé pacifista e da tecnicista, que de resto não se deixa explicar, se explica a partir da tendência à neutralização, rumo à qual o espírito europeu se decidiu no século XVII e que ele continuou perseguindo como que sob um destino, até bem dentro do século XX. (Schmitt, 1992, p.116)

A conseqüência desta despolitização é o surgimento da teoria do "Estado neutro" defendida pelo liberalismo no século XIX. A hipótese liberal de que a sociedade deve, 
ela mesma, encontrar formas de auto-regulação econômica e política de acordo com o equilíbrio dos interesses particulares - conseqüentemente, excluindo o Estado ou tornando-o mero instrumento desta regulação, segundo uma idealidade técnica normativa neutra -, se constitui em força motriz desse processo de despolitizaçãoneutralização. Schmitt conclui que esse processo se completou, na era da técnica, no quadro político do liberalismo, e atinge todas as tendências e correntes políticas dos nossos dias.

Nada mais moderno hoje que a luta contra o político. Financistas americanos, técnicos da indústria, socialistas marxistas e revolucionários anarcosindicalistas unem suas forças com a palavra de ordem de que é preciso eliminar a dominação não objetiva do político sobre a objetividade da vida econômica. Devem apenas subsistir tarefas técnicas, organizacionais, econômicas, sociológicas, os problemas políticos são desconsiderados. Aliás, o tipo de pensamento econômico e técnico que hoje domina é incapaz de perceber uma idéia politica. O Estado moderno realmente parece que se tornou aquilo que Max Weber nele vê: uma grande empresa. (Schmitt, 1988b, p.73)

Esse processo de neutralização-despolitização consiste não só em converter determinadas realidades e termos políticos em realidade e termos neutros (técnicos) e "apolíticos", como também opera um deslocamento semântico.

Assim [diz Schmitt], no pensamento liberal o conceito político de luta se transforma, no aspecto econômico, em concorrência, e no outro aspecto, "espiritual", em discussão; no lugar de uma clara distinção dos dois diferentes status "guerra" e "paz", entre dinâmica da eterna concorrência e da eterna discussão. O Estado se torna em sociedade e então, de um lado, espiritual-ético, numa representação ideológica humanitária da humanidade; de outro lado, numa unidade econômico-técnica de um sistema unitário de produção e de comércio. Da vontade, dada na situação de luta e completamente óbvia, de repelir o inimigo, surge um ideal ou programa social, construido racionalmente, uma tendência ou um cálculo econômico. De um povo unido politicamente surge, de um lado, um público culturalmente interessado, e de outro lado em parte um pessoal da fábrica e do trabalho, em parte uma massa de consumidores. Da dominação e do poder surgem, no pólo espiritual, propaganda e sugestão de massas, e no pólo econômico, controle. (Schmitt, 1992, p.98-9)

Finalmente, o liberalismo caracteriza-se pela dinâmica da discussão. As instituições liberais, observa Schmitt, são capazes de "discussões perpétuas", mas incapazes de uma "decisão última". Com efeito, o decisionismo schmittiano é o antípoda do "discussionismo" liberal. Para Schmitt, política significa decisão. Tal ponto de vista não está presente na visão de mundo do liberalismo, o qual se caracteriza por uma determinada forma de pensar a vida segundo a lógica da discussão e a metafísica da indecisão. Schmitt faz suas as palavras de Donoso Cortés, que define a burguesia como uma "classe discutidora" que não enfrenta a decisão e que "coloca toda a atividade política no discurso, na imprensa e no parlamento..." (Schmitt, 1988b, p.68).

A discussão neutraliza a política, pois desloca a decisão para a esfera do interminável discurso que emascula toda tensão conflituosa. O discurso liberal-parlamentar baseia-se na idéia de que "a verdade procede do livre conflito das opiniões" 
(Schmitt, 1988a, p.45), a qual se constitui no princípio da discussão. Em relação à "ética da discussão" - como denomina Kervégan, referindo-se ao aspecto da crítica schmittiana ao liberalismo -, seu caráter nuclear é a "representação de uma constituição pública da verdade (ou da justiça) graças a um procedimento institucionalizado de argumentação e de discussão, fundado sobre regras públicas e reconhecidas". A elaboração teórica, bastante sistemática deste tipo de procedimento, está na "ética do discurso" de Habermas, a qual se coloca frontalmente contra o procedimento decisionista de Schmitt (Kervégan, 1982, p.123).

A formulação mais exata e mais elaborada da ética liberal da discussão pode ser encontrada num pensador que, se leu atentamente Carl Schmitt, apresenta-se como o adversário mais resoluto de toda forma de decisionismo: Jürgen Habermas. Sem dúvida, não é exagerado reconhecer na sua ética comunicacional o desenvolvimento sistemático daquilo que Schmitt apresenta como o próprio coração do liberalismo.

De fato, para Schmitt, a força da ação política está na decisão. Para Habermas, a decisão deve ter como horizonte o consenso racional, podendo, por ele, ser ultrapassada.

Definido como uma "visão de mundo", "como um sistema metafísico global e conseqüente" (Schmitt, 1988a, p.44), o liberalismo desenvolveu uma forma de governo ajustada à sua concepção política: o parlamentarismo. A crítica schmittiana ao liberalismo se dirige, especificamente, ao parlamentarismo, apontando seus impasses e contradições.

O sistema parlamentar tem por base o debate e a publicidade que remontam à concepção liberal do indivíduo portador do direito da liberdade de opinião. Por isso, o parlamentarismo se define como o "governement by discussion". Contudo, esta forma de governo apresenta problemas. Em primeiro lugar, o discurso liberal-parlamentar, no uso da dialética do debate das opiniões, faz prevalecer o mero enfrentamento de posições partidárias rígidas que lutam a qualquer preço para que suas idéias triunfem, prevalecendo, assim, os interesses particulares. Em segundo lugar, o antigo ideal moral liberal da superioridade do indivíduo na afirmação da sua autonomia aquilo que instrumentaliza ética e politicamente o debate e a publicidade - encontrase, hoje, sob suspeita, na medida em que os indivíduos são manobrados na moderna sociedade de massas pelos diversos mecanismos sociais de manipulação das consciências. Em terceiro lugar, a ação pública parlamentar traz como resultado do jogo de opiniões um conflito de interesses, fazendo prevalecer o lado privado de grupos, e não o interesse público. Finalmente, o parlamentarismo substitui a legitimidade pela legalidade como forma de dar autenticidade e fundamentar a política e a sua prática.

É precisamente esta última contradição que leva Schmitt a aprofundar sua crítica ao liberalismo, a qual move-se na contraposição entre a noção de democracia, tal como Schmitt a compreende, e o liberalismo. 
Liberalismo e democracia devem ser distinguidos, pois manifestam uma radical oposição:

oposição entre um individualismo liberal marcado por um pathos moral e um sentimento democrático de Estado dominado por ideais essencialmente políticos... É a oposição, em suas últimas profundezas invencivel, entre a consciência liberal do homem-indivíduo e a homogeneidade democrática. (Idem, p.116)

O liberalismo opera com a noção de igualdade abstrata e formal entre os homens. Por isso, a igualdade liberal é antes uma "democracia de massa". Remontando a Rousseau, a concepção de democracia de Schmitt, marcada pelo princípio da igualdade, destaca este aspecto da homogeneidade, da busca da identidade entre governantes e governados, enfim, da manifestação da "vontade geral" do povo. A identidade que Schmitt reclama, possível na democracia, é a identificação das instâncias de poder que não se autonomizam (como na concepção da democracia liberal) em relação aos destinatários dos atos de decisão política deste mesmo poder. Trata-se, pois, da

identidade dos governantes e dos governados, do dirigente e dos dirigidos, a identidade do sujeito e do objeto da autoridade estatal, a identidade do povo com sua representação no parlamento, a identidade entre a lei e o Estado, e, em última instância, a identidade do quantitativo (maioria numérica ou unanimidade) e do qualitativo (justeza de lei). (Idem, p.33)

Deste ponto de vista, Schmitt pode afirmar que "a fé no parlamentarismo, em um governement by discussion, pertence ao universo do pensamento do liberalismo. Ela não pertence à democracia" (Idem, p.105).

A concepção de democracia para Schmitt repousa no princípio da identidade entre aqueles que governam e os que são governados: "uma definição da democracia deve, pois, partir da representação da identidade típica de todo pensamento democrático (identidade entre dominadores e dominados, entre governantes e governados, entre Estado e povo, entre sujeito e objeto da autoridade política)" (Idem, p.126). Se "toda democracia, incluindo a parlamentar, descansa fundamentalmente sobre 0 pressuposto de homogeneidade plena e indivisível" (Schmitt, 1971, p.64), a conexão entre 0 povo e o público, entre o citoyen e o súdito, entre o representante e 0 representado, própria da democracia, tende a ser incompatível com o sistema da representação política do cidadão no parlamento, onde a idéia da soberania popular é subvertida e a radical autodeterminação do povo é substituída por engenhosos mecanismos "democráticos" indiretos: o parlamento, o deputado, a publicidade, os grupos de pressão (lobbies).

Contudo, nem mesmo a força do conceito de identidade e igualdade própria à noção da imanência do poder na democracia pode excluir o mecanismo de representação. Na medida em que não há Estado sem representação, salvo em casos extremos de uma democracia radical, a identidade entre governantes e governados não é 
absolutamente imediata. "Não há, pois, nenhum Estado sem representação, porque não há nenhum Estado sem forma política. Em todo Estado tem que haver homens que possam dizer: L'état c'est nous" (Schmitt, 1982, p.207). A questão para Schmitt não está na exclusão pura e simples da representação, mas na sua qualificação. Em primeiro lugar, o que autoriza e dá veracidade aos mecanismos de representação é a sua legitimidade e não a mera legalidade de uma eleição, por exemplo. Uma representação legítima intensifica e promove a totalidade política e se aproxima do elemento identitário da democracia. Em segundo lugar, a representação se dá na esfera do público. Não há representação de interesses privados. A representação (Repräsentation) política é diferente da representação (Vertretung) do direito privado, em que a figura do delegado age em nome de outrem. Finalmente, a representação deve ser de caráter existencial. "A representação não é um fenômeno de caráter normativo, não é um procedimento, mas algo existencial. Representar é fazer perceptível e atualizar um ser imperceptível mediante um ser de presença pública" (Idem, p.209).

A era em que vivemos é, para Schmitt, a "época das neutralizações e das despolitizações". ${ }^{4} \mathrm{~A}$ modernidade exprime a fase derradeira de um longo processo histórico de despolitização. O liberalismo reflete esta tendência. O paradoxal é que 0 liberalismo moveu-se e promoveu o princípio da autonomia nos diversos aspectos da vida humana: na moral, na estética, na religião etc. Contudo, negou à política a possibilidade deste mesmo princípio. De um lado, o liberalismo afirma e enaltece a competição entre os homens na vida social e cultural e a concorrência na economia, de outro lado, silencia-se sobre o caráter antagônico na política. Reafirmar o político para Schmitt significa, justamente, reconhecer e postular a autonomia do político. Como observa L. Strauss, "Schmitt gostaria de reconhecer a autonomia do político contra o liberalismo, permanecendo na continuidade dos esforços liberais no sentido da autonomia"(Straus in: Schmitt, 1988a, p.193).

Hegel defende para a constituição do Estado os dois princípios que Schmitt emprega no conceito de democracia: a identidade entre governantes e a erradicação da heterogeneidade. Com efeito, a aplicação teórica e as conseqüências práticas destes conceitos são diferentes nestes autores determinando, assim, um uso especulativo da noção de identidade e totalidade para Hegel, e um uso existencial para Schmitt. No que se refere, por exemplo, à idéia de Estado total, Schmitt elogia a noção hegeliana do todo como infinidade finita, e critica a representação da totalidade como "identidade substancial averroísta entre a parte e o todo" (Schmitt, 1991, p.12).

Schmitt reconhece a importância histórica na filosofia política alemã da distinção hegeliana entre Estado e sociedade civil: "a doutrina alemã do Estado, sob a influência

4 A questão da despolitização constitui, entre outros, tema da análise da filosofia politica de $\mathrm{H}$. Arendt. Com base em outro tipo de argumentação, Arendt mostra que a busca da segurança e dos interesses privados, a conservação da vida e não mais a liberdade (pública), leva, conjugada com a massificação, à insensibilidade e à atrofia do sentimento político. 
da filosofia do Estado de Hegel, não renunciou de saída à idéia de que o Estado, frente à sociedade, é algo de distinto e de superior" (Schmitt, 1992, p.48). Este "estado universal" hegeliano, como o chama Schmitt, transcende a sociedade e se diferencia do Estado total schmittiano na medida em que neste ocorre uma politização total da sociedade. É o Estado em que tudo é político, inclusive a economia. Esse investimento estatal da sociedade elimina esferas sociais neutras. Diferentemente de Hegel, 0 Estado schmittiano não é a superação da sociedade civil-burguesa (mantendo com ela uma relação de fundação regressiva e diferenciação progressiva na lógica da mediação recíproca entre a esfera política e a esfera social), mas uma totalização política que envolve tanto o Estado como a sociedade.

A intervenção estatal ou o investimento político na esfera social não é tão forte e linear em Hegel. O caráter da racionalidade ético-política do Estado (o que define a sua "modernidade" já a partir de Hobbes) significa, para Hegel, propor a medida da universalidade ética (pública, política) à particularidade dos interesses privados da sociedade civil-burguesa. É nessa perspectiva que se pode avaliar a posição crítica de Hegel diante do liberalismo.

Para Hegel, a esfera da sociedade civil-burguesa (bürgerliche Gesellschaft) caracteriza-se pela união formal de indivíduos que, pelo trabalho, buscam a satisfação das necessidades privadas. A sociedade civil-burguesa é o "estado da necessidade e do entendimento" marcado pela liberdade subjetiva dos seus membros. Regulada pelo direito privado e pelas leis do mundo, ela é incapaz de, por si só, alcançar o status político e o interesse público. O Estado, então, surge como um momento político necessário, e se erige em forma superior da vida social da Sittlichkeit, capaz de gerar uma universalidade que se distingue dos interesses privados da esfera social e econômica. Nesse sentido, a distinção e a relativa autonomia da sociedade civil-burguesa diante do Estado não autoriza a primazia do econômico sobre o político, do privado sobre o público.

A idéia liberal do poder do Estado como algo negativo e exterior, o qual inevitavelmente tende a se tornar abusivo se não for limitado, patenteia uma concepção antípoda ao conceito hegeliano de poder do Estado caracterizado como algo positivo e imanente à vida política dos cidadãos. Se para o liberalismo é inevitável conceder ao Estado o monopólio da força - até um dia em que, finalmente, os homens possam viver sem a necessidade dessa coação estatal - resguardando a sociedade civil contra o abuso do poder, circunscrevendo-o dentro de limites e sob o controle jurisdicional da sociedade; para Hegel, a existência deste monopólio como poder do Estado constitui uma exigência do Estado moderno, sem o qual os indivíduos não cumprem a destinação racional de sua natureza e a liberdade se afigura como uma palavra vazia e formal. O Estado não é meio, mas fim. É ele que limita e não pode ser objeto de limitação. Nesse sentido, a perspectiva hegeliana representa 0 ponto culminante da concepção positiva de Estado e de poder que remonta a Platão e Aristóteles. 
Se Hegel valoriza o Estado compreendendo a sociedade civil-burguesa como meio para a realização de um fim político superior; se concebe a impossibilidade da vida humana sem sua destinação política, em que a potência universalizadora do Estado envolve pacífica e solidariamente os indivíduos, não se pode estigmatizar sua filosofia política de "estatolatria". O Estado hegeliano não ostenta uma unidade indiferenciada que regula de forma autoritária o agir dos indivíduos e a sua liberdade. Não encobre a força autocrática que cerceia as liberdades fundamentais do cidadão, nem sustenta o olho invisível que controla a sociedade impondo-lhe os rumos de acordo com a vontade do príncipe. Também não fundamenta o intervencionismo que liquida com a livre iniciativa dos cidadãos. A instância da esfera privada voltada para a liberdade dos indivíduos e organizada segundo princípios econômicos da livre concorrência da sociedade civil-burguesa demanda um sistema social avesso à dominação estatal. A ingerência do Estado nessa sociedade torna-se mera extensão da esfera política, a qual, por sua vez, se rebaixa imiscuindo-se nos assuntos da particularidade da má infinitude da vida da necessidade, corrompendo, assim, o caráter necessário da soberania e supremacia do político. Na passagem de um no outro, não só a sociedade civil se descaracteriza, como também o Estado se liquida em sua verdadeira essência. Para Hegel, a liberdade subjetiva (de ser proprietário e sujeito empreendedor) insere-se na sociedade civil-burguesa e exige 0 afastamento do Estado, até mesmo para preservar o caráter de superioridade da instância política que o Estado representa e constitui.

De um lado, Hegel compartilha com o ideal liberal no acolhimento do postulado da autonomia da sociedade, na sua capacidade de auto-subsistência e do espaço que ela representa para a liberdade dos indivíduos na livre administração dos seus negócios e na promoção do bem-estar da particularidade. De outro lado, repudia a idéia liberal do privilégio da sociedade civil e do caráter negativo do Estado na sua compreensão de mal necessário ou de mero instrumento dos interesses privados.

Quando os mecanismos sociais de formação do indivíduo, como as instituições escolares e as instituições profissionais (as corporações), não conseguem minorar as contradições dessa sociedade, particularmente a pauperização e o aprofundamento da desigualdade das riquezas, a ação da autoridade pública na sociedade torna-se uma exigência para a manutenção do equilíbrio social, visando à própria sobrevivência da sociedade e ao funcionamento da ordem privada. A intervenção do Estado revela-se decisiva para evitar a desagregação social e para coibir que o indivíduo sucumba na limitação econômico-social de sua existência e jamais alcance a plenitude de sua vida no Estado como citoyen.

Desta forma, a concepção hegeliana de Estado, a sua sensibilidade ao princípio da liberdade subjetiva da modernidade, o qual se realiza efetivamente na sociedade civil-burguesa, impede a "politização" total da sociedade, tal como Schmitt a concebe. A posição crítica de Hegel e de Schmitt diante do liberalismo decorre da forma como ambos elaboram o conceito de Estado e a noção de poder. 
Em bases diferentes, mas com o mesmo objetivo de destacar o conceito do político como elemento decisivo da sociabilidade, tanto Hegel como Schmitt expõem teses que atestam o caráter positivo do Estado na afirmação do político. Ambos recusam a instrumentalização do Estado em favor da sociedade, o que leva à negação do político ou à sua neutralização e despolitização. Tanto um como outro repudiam a idéia liberal do privilégio da sociedade civil ante o Estado, o qual surge apenas como mal necessário ou mero instrumento dos interesses privados. Portanto, a crítica ao liberalismo de Hegel e de Schmitt significa a crítica à negação do político e à instrumentalização do Estado: a hipótese de que a sociedade deve, ela mesma, encontrar formas de auto-regulação econômica e política excluindo como objetivo final o Estado.

O liberalismo vincula o político às liberdades individuais, fazendo prevalecer do ponto de vista institucional o direito como fim e a organização estatal (política) como meio. A inclinação à normatividade, isto é, ao governo da lei como forma política de autoridade legítima, acaba prevalecendo sobre o político, negando, assim, sua autonomia. A racionalidade da norma e o caráter irredutível da liberdade individual, a plausibilidade moral dos direitos individuais, associada ao consenso dos homens sobre a conveniência da paz e sobre o valor dos acordos como idéia ética reguladora da sociabilidade, são pressupostos para o político, o qual acaba se desqualificando diante da "racionalidade" da lei, da positividade do direito e da legalidade dos procedimentos. A norma e o ordenamento jurídico, embora provenientes da vontade do legislador, tomam-se auto-suficientes, dotados de uma fundamentação para além da política.

A posição de Hegel não pode ser reduzida à segurança da simplicidade da filosofia do "entendimento" do liberalismo. A pretensão da separação entre direito, ética e política é criticada por Hegel na própria organização temática da Filosofia do Direito (Direito abstrato, Moralidade e Eticidade), a qual revela não só o encadeamento lógico dessas três esferas, como também a intenção especulativa de Hegel de ver no Estado moderno a ex-posição e a realização efetiva da política. Por isso, a Filosofia política de Hegel se coloca também, de algum modo, para além do político, na medida em que a sua possível autonomia se dissolve na racionalidade do Estado moderno e, por ele, se normatiza. Desta forma, Hegel não rejeita qualquer tipo de normativismo, apenas aquele do entendimento abstrato que separa a norma, a lei, o direito de sua fundamentação racional (a "política" do Estado). A universalidade deve se exprimir na norma e não na particularidade. Assim, a política de Hegel, por força da lógica universalizante da razão, volta-se para a universalidade da norma, e não para a presença existencial da decisão.

O existencialismo político de Schmitt ressalta que o que importa não é a finalidade, o resultado ou o sentido da decisão política, mas o fato existencial da própria decisão. De fato, Schmitt destaca esse aspecto na teoria política, dizendo: "todas as representações essenciais da esfera do espiritual do homem são existenciais e não normativas" (Idem, p.111). O critério de validade deste existencialismo político 
não é o direito, a positividade ou normatividade da lei, a justiça, o bem, a virtude ou qualquer outra determinação ético-racional, mas o ato de ser do político que se exprime pela decisão. Toda unidade política existente tem seu valor e sua razão de existência não na justiça ou na conveniência de normas, mas em sua própria existência. O que existe como magnitude política é juridicamente considerado digno de existir (Schmitt, 1982a, p.46). Esse caráter metafísico-existencial do político é sustentado e afirmado mais pela vontade dos atos de decisão do que pela racionalidade da norma.

Uma constituição não se apóia em uma norma cuja justiça seja o fundamento de sua validez. Apóia-se em uma decisão politica surgida de um Ser político acerca do modo e forma do próprio Ser. A palavra "vontade" denuncia - em contraste com toda dependência em relação a uma justiça normativa ou abstrata - o essencialmente existencial deste fundamento de validez. (Idem, p.94)

A intenção schmittiana é, com base nesse ponto de vista existencial, denunciar a ilusão da racionalidade da política burguesa na tentativa de instaurar um Estado de direito, no qual o poder está distribuído, regulado e limitado por um ordenamento jurídico "neutro" que se diz apolítico. No entanto, o problema nos Estados modernos consiste em encontrar meios de fundamentação desta legalidade. A razão moderna recusa a fundamentação que não seja pela via da racionalidade. Apega-se àquilo que ela apresenta como única possibilidade: a positividade da norma que se justifica a si mesma. Schmitt quer chamar a atenção para essas contradições, e mostrar que a fundamentação do político escapa à obviedade da razão liberal-burguesa. Opera, então, com a hipótese do "vazio" na fundamentação do político, escolhendo como única possibilidade da sua explicação o recurso ao seu irredutível caráter existencial.

RAMOS, C. A. Schmitt's and Hegel's criticism of liberalism. Trans/Form/Ação (São Paulo), v.18, p.105-119, 1995.

- ABSTRACT: This article aims to discuss the political philosophy of liberalism, from the critical analyses presented by Schmitt and Hegel. The former bases his criticism on the perspective of "political existentialism"; the latter argues on the basis of the rationality of the modern State. Both stress the positive value of the State and criticize the negation of the politician which is advocated by liberalism.

- KEYWORDS: Liberalism; State; politics.

\section{Referências bibliográficas}

1 BONVECCHIO. Decisionismo. La dottrine politica di C. Schmitt. Milano: s.n. 1994.

2 BOURGEOIS, B. Le droit naturel de Hegel (1802-1803). Commentaire. Contribution à l'étude de la genèse de la spéculation hégélienne à Iena. Paris: Vrin, 1986. 
3 BOURGEOIS, B. El pensamiento politico de Hegel. Trad. A. C. Leal. Buenos Aires: Amorrortu, 1972.

4 DOREMUS, A. Introduction à la pensée de C. Schmitt. Archives de Philosophie, v.45, 1982.

5 FLICKINGER, H. G. et al. Apresentação do político. In: O conceito do político. Trad. A. L. M. Valls. Petrópolis: Vozes, 1992.

6 Die autonomie des Politischen. Herausgegeben von Hans-Georg Flickinger. Weinheim: Acta Humaniora, 1990.

7 FREUND, J. L'essence du politique. Paris: Sirey, 1965.

8 HOBBES, T. O Leviatã. Trad. João Paulo Monteiro e Maria Beatriz Nizza da Silva. São Paulo: Abril Cultural, 1974. (Coleção Os Pensadores)

9 ILTING, K. H. The structure of Hegel's philosophy of right. In: Hegel's Political Philosophy, problems and perspectives. PELCZYNSKI, Z. A. (Ed.) Cambridge: Cambrïge University, 1971.

10 KLAUS, H., LIETZMANN, H. Carl Schmitt und die Liberalismus-kritik. S.l.: Leverkussen Leske \& Budrich, 1988.

11 KELSEN, H. Teoria pura do direito. 2.ed. Trad. J. B. Machado. São Paulo: Martins Fontes, 1987.

12 KERVÉGAN, J. F. De la démocratie à la représentation. In: Philosophie, n.13, Paris: Minuit, 1987a.

13 . Hegel et l'état du droit. Archives de Philosophie, v.50, n.1, jan./mar. 1987b.

14 Hegel, Carl Schmitt. Le politique entre spéculation et positivité. Paris: PUF, 1982.

15 . Politik und Vernünftigkeit. Anmerkungen zum Verhältnis zwischen Carl Schmitt und Hegel. In: Der Staat, 27 Band. Berlin: Heft 14, 1988.

16 LOCKE, J. Segundo tratado sobre o govemo civil. São Paulo: Abril Cultural, s.d. (Coleção Os Pensadores)

17 LÖWITTH, K. Le décisionnisme (occasionnel) de C. Schmitt. Les Temps Modemes, n.544, 1991.

18 LUKÁCS, G. El assalto a la razón. Trad. W. Roces. Barcelona: Grijalbo, 1976.

19 LUTZ, A. B. Johannes Popitz und Carl Schmitt. Zur Wirtschaftlichen Theorie des totalen Staates. In: Deutschland. München: C. H. Beck, 1972.

20 MARCUSE, H. La lutte contre le libéralisme dans la conception totalitaire de l'état. In: Culture et Societé. Paris: Minuit, 1970.

21 MARTINEZ, J. C. El pensamiento junídico-político de Carl Schmitt. Santiago de Compostela: Porto y Cia., 1950.

22 MARX, K. Marx, Engels Werke. S.l.: Dietz, 1958.

23 MASCHKE, G. Der Tod des C. Schmitt, Apologie und Polemik. Wien: Karalinger, 1987.

24 MEIER, H. C. Schmitt, L. Strauss und der "Begriff des Politischen". Stuttgart, 1988.

25 OUARTSCH, H. (Org.) Complexio Oppositorum Über Carl Schmitt. Berlin: Duncker \& Humblot, s.d.

26 RIEDEL, N. Materialen zu Hegels Rechtsphilosophie. Herausgegeben von M. Riedel. Frankfurt am Main: Suhrkamp, 1975. band I e II.

27 Z Zwischen Tradition und Revolution. Studien zu Hegels Rechtsphilosophie. Stuttgart: Klett-Cotta, 1982.

28 RITTER, J. Hegel et la révolution française, suivi de personne et proprieté selon Hegel. Paris: Beauchesne, 1970. 
29 RUMPF, H. Carl Schmitt und Thomas Hobbes; ideelle Beziehungen und aktuelle Bedeutung. Berlin: Duncker \& Humblot, 1972.

30 SCHMITT, E. Politische Theologie. Vier Kapitel zur Lehre von der Souveränität. 2.ed. München-Leipzig: Duncker \& Humblot, 1934.

31 _. Der Begriff des Politischen. 4.ed. Berlin: Duncker \& Humblot, 1963.

32 _. Die Diktatur. Von der Anfägen des modernen Souveränitätsgedankens bis zum proletarischen Klassenkampf. 2.ed. München-Leipzig, 1964.

33 _. Politische Romantik. München-Leipzig: Duncker \& Humblot, 1925/1968.

34 L Legalidad y legitimidad. Trad. J. D. Garcia. Madrid: Aguilar, 1971.

35 _. Der Leviathan in der Staatslehre des Thomas Hobbes. Köln: HohenheimMaschke-Cotta, 1982a.

36 _. Verfassungslehre. 5.ed. München-Leipzig: Duncker \& Humblot, 1970. Trad. espanhola Teoría de la Constitución. Trad. F. Hyala. Madrid: Alianza, 1982b.

37 _. Die geistesgeschichtliche Lage des heutigen Parlamentarismus. MünchenLeipzig: Duncker \& Humblot, 1926. Paris: Seuil, 1988a. Tradução francesa Parlementarisme et démocratie.

38 _. Théologie politique I et II. Trad. J. Schlegel. Paris: Gallimard, 1988b.

39 _. L'État comme mécanisme. Temps modemes, n.544, p.1-14, nov. 1991.

40 - O conceito do político. Apres. H. G. Flickinger. Trad. A. L. M. Valls. Petrópolis:

Vozes, 1992.

41 SCHWAB, G. The challenge of the exception: an introduction to the political ideas of Carl Schmitt between 1921 and 1936. Berlin: Duncker \& Umblot, 1970.

42 STRAUSS, L. Droit naturel et histoire. Trad. M. Nathan, E. de Dampierre. Paris: Plon, 1954.

43 TELOS. A quartely of critical thought. Especial issue on Carl Schmitt. New York: Telos, 1987. n.72.

44 TOMMISSEN, P. (Ed.) Schmittiana I, II. Weinheim: VHC, 1990.

45 WEIL, E. Hegel et l'État. Paris: Vrin, 1974.

46 WIEK, K. La doctrine politique du national-socialisme: Carl Schmitt. Archives de Philosophie du Droit e de Sociologie Juridique, v.IV, 1934.

47 WOLIN, R. Carl Schmitt. L'Existencialisme Politique et L'État total. Les Temps Modemes, v. 45, n. $523,1990$. 